\title{
Immediate balloon deflation method in endoscopic papillary large balloon dilation for extraction of difficult bile duct stones*
}

\author{
Duk Joo Choi, Yeon Suk Kim ${ }^{\#}$, Jung Ho Kim, Yang Suh Ku, Min Su Ha, Ju Hyeon Kim \\ Department of Internal Medicine, Gachon University Gil Medical Center, Incheon, South Korea \\ Email: " \\ Received 17 February 2013; revised 27 March 2013; accepted 3 May 2013 \\ Copyright (C) 2013 Duk Joo Choi et al. This is an open access article distributed under the Creative Commons Attribution License, \\ which permits unrestricted use, distribution, and reproduction in any medium, provided the original work is properly cited.
}

\begin{abstract}
Background/Aims: Recently, endoscopic papillary large balloon dilation (EPLBD) using a large balloon (12 $20 \mathrm{~mm}$ ) for extraction of difficult common bile duct (CBD) stones has been widely accepted with favorable outcomes. However, there is no consensus with regard to the ballooning time. The aim of our study was to evaluate the efficacy and safety of immediate balloon deflation in EPLBD for the treatment of difficult bile duct stone. Methods: This was a retrospective study of 80 consecutive patients with bile duct stones who were treated with an immediate balloon deflation method in EPLBD combined with endoscopic sphincterotomy (EST) between January 2010 and December 2012. Overall success rate, success rate at first ERCP, and the frequency of mechanical lithotripsy for complete stone removal were assessed for efficacy and safety was evaluated by assessing major complications. Results: Overall success rate for complete stone removal was high $(\mathbf{7 8 / 8 0}, 97.5 \%)$ and success rate for complete stone removal at first ERCP was $86.3 \%$ (69/80). The use of mechanical lithotripsy was $0 \%$ $(0 / 80)$. The overall complication rate was favorable $(5 / 80,6.3 \%)$. PostERCP pancreatitis was observed in 3 patients (two: mild, one: moderate). In subgroup analysis, the presence of periampullary diverticulum was the only factor affecting the success rate at first ERCP. Conclusion: This study demonstrated the favorable outcome of immediate balloon deflation for treatment of difficult CBD stones and can be considered for clinical application.
\end{abstract}

Keywords: Endoscopic Papillary Large Balloon Dilation; Ballooning Time; Immediate Balloon Deflation; Difficult

\footnotetext{
*Conflicts of Interest: The authors have no financial conflicts of interest.

${ }^{\#}$ Corresponding author.
}

\section{Bile Duct Stone}

\section{INTRODUCTION}

Endoscopic papillary large balloon dilation (EPLBD) has recently been used for extraction of difficult bile duct stones. This technique requires of use of a large balloon ( $\geq 12 \mathrm{~mm}$ in diameter) for papillary dilation and is almost always combined with endoscopic sphincterotomy (EST).

In 2003, Ersoz et al. [1] first described the use of EPLBD after EST for removal of difficult bile duct stones. Since then, several studies of EPLBD [2-9] for treatment of difficult bile duct stones have reported favorable outcomes and acceptable complication rates. In addition, a recent meta-analysis [10] reported that EPLBD should be considered as an alternative for patients in whom EST could not be routinely performed; it was also recommended for removal of large or difficult common bile duct stones in patients with an underlying coagulopathy or need for anticoagulation following endoscopic retrograde cholangiopancreatography (ERCP) because cases of hemorrhage in EPLBD are fewer than in EST.

However, so far, there has been no consensus with regard to ballooning time [10]. In most studies on EPLBD, the balloon was kept inflated for a certain period after the waist of the balloon had disappeared under endoscopic and fluoroscopic guidance. Unlike other studies, a balloon used in this study was deflated immediately after disappearance of the waist of balloon had been achieved. The aim of this study was to evaluate the efficacy and safety of an immediate balloon deflation method.

\section{MATERIALS AND METHODS}

\subsection{Patients}

Between January 2010 and December 2012, a total of 80 patients who were hospitalized for extraction of difficult 
bile duct stones and never exposed to ERCP were enrolled in this study and retrospective analysis was performed. All enrolled patients were treated with EPLBD (balloon size $12 \mathrm{~mm}$ - $20 \mathrm{~mm}$ ) combined with a limited EST. Difficult bile duct stones were defined as bile duct stone(s) greater than $15 \mathrm{~mm}$ in diameter (if multiple, a diameter in the largest one) and/or having a periampullary diverticulum (PAD), which could cause technical difficulty for conventional EST. All enrolled patients were 18 years of age or older and informed consent was obtained before ERCP. Patients who had a history of previous EST or EPLBD were excluded from this study. Patients who underwent precut papillotomy, which could compromise the assessment of procedure-related complications for bile duct access, were excluded. For the same reason, patients with clinically proven acute pancreatitis were also excluded. Other exclusion criteria included concomitant pancreatic or biliary malignancy, definite benign biliary stricture, combined with choledochoduodenal fistula, hepatolithiasis, and altered anatomy due to a prior operation, such as Billroth anastomosis and hemostatic disorders. Bile duct stones that were positive on initial imaging studies (US, CT, or MRCP) but unidentified on ERCP were also excluded.

\subsection{Methods}

After obtaining informed consent, all ERCP was performed using a side-viewing duodenoscope (TJF-240; Olympus Optical Co, Ltd, Tokyo, Japan) with sedation with midazolam plus opioids (demerol or fentanyl). Propofol infusion was added when deep sedation was needed. Selective bile duct cannulation was achieved using the pull-type papillotome preloaded with a 0.035 -inch guidewire. Minimal pancreatogram was performed only when a guidewire assisted bile duct cannulation was not secure. After successful selective bile duct cannulation, a cholangiogram was performed and the diameter of the stone (the largest one if multiple) with CBD diameter was measured on the initial cholangiogram. Distal CBD arm and CBD angle were also measured on the initial cholangiogram and acute $\mathrm{CBD}$ angle was defined as a $\mathrm{CBD}$ angle less than $135^{\circ}$. A limited sphincterotomy (an incision less than $1 / 3$ of the papillary roof) was performed and a balloon catheter (CRE Esophageal/Pyloric, maximum diameter 12, 15, 18, or $20 \mathrm{~mm}$; length $5 \mathrm{~cm}$, Boston Scientific, Natick, MA) dilation was chosen according to the diameter of CBD and the stone was introduced and gradually inflated up to the maximal pressure under endoscopic and fluoroscopic guidance. As soon as the disappearance of the balloon waist was confirmed, balloon deflation was performed immediately without keeping the balloon inflated.

Ballooning time was defined as the period between attainment of maximal pressure and deflation of the bal- loon. After balloon deflation, stone extraction using a retrieval balloon catheter was attempted in order to avoid impaction. If the stone extraction using a retrieval balloon failed after four attempts, mechanical lithotripsy was attempted. Complete stone removal was documented with a final cholangiogram. If a residual stone was found, a plastic stent (7Fr single pigtail or double pigtail) was placed and a second ERCP was reattempted within three or four days. Routine pancreatic stenting was not intended.

Complications were evaluated according to the consensus criteria of Cotton et al. [11] Efficacy was evaluated by assessing the success rate for complete stone removal at the first ERCP session and the frequency of mechanical lithotripsy. Technical failure was considered as either failure of complete stone clearance at the first ERCP attempt or overall failure of stone extraction. Safety was evaluated by assessing the incidence of major postprocedure complications (postERCP pancreatitis, bleeding, and perforation).

\subsection{Statistical Analysis}

Continuous variables are expressed as mean \pm standard deviation (SD). Median with range was used for the expression of continuous variables that did not show normal distribution. Student's t test was used for comparison of mean values between the two groups. The MannWhitney's test was used in the analysis of continuous variables that did not show normal distribution. Chisquare tests were used in the analysis of categorical variables. A p value of less than 0.05 was considered statistically significant.

\section{RESULTS}

\subsection{Patient Characteristics (Table 1)}

Mean age of all enrolled patients was $70.98 \pm 10.21 .40$ patients were male and 40 were female. Bile duct stone size was $14.43 \pm 4.44 \mathrm{~mm}$. Multiple stones were observed in $44 / 80(55 \%)$ patients. Bile duct diameter was $20.33 \pm 5.74 \mathrm{~mm}$. The size of the CRE balloon used for dilation was as follows: $12 \mathrm{~mm}$ in 18 patients, $15 \mathrm{~mm}$ in 37 patients, $18 \mathrm{~mm}$ in 18 patients, and $20 \mathrm{~mm}$ in seven patients. Balloons over $18 \mathrm{~mm}$ were used in 25 patients $(31.3 \%)$. PAD was present in $45 / 80$ (56.3\%) patients. Mean CBD angle was $143.53^{\circ} \pm 16.06^{\circ}$ and mean distal CBD arm was $37.30 \pm 12.36 \mathrm{~mm}$. Acute CBD angle $\left(\leq 135^{\circ}\right)$, which could cause difficulty in removal of bile duct stones, was observed in 40 patients (40\%).

\subsection{Efficacy and Safety Evaluation (Tables 2 and 3)}

Overall success rate for complete stone removal was 
Table 1. Baseline characteristics of patients and subgroup analysis.

\begin{tabular}{|c|c|}
\hline \multicolumn{2}{|c|}{ Total $(n=80)$} \\
\hline Age & $70.98 \pm 10.21$ \\
\hline \multicolumn{2}{|l|}{ Gender } \\
\hline Male:Female & $40(50.0 \%): 40(50.0 \%)$ \\
\hline \multicolumn{2}{|l|}{ Balloon size (mm) } \\
\hline 12 & $18(22.5 \%)$ \\
\hline 15 & $37(46.3 \%)$ \\
\hline 18 & $18(22.5 \%)$ \\
\hline 20 & $7(8.8 \%)$ \\
\hline Stone size (mm) & $15.05 \pm 3.75$ \\
\hline Multiple stones & $44(55.0 \%)$ \\
\hline \multicolumn{2}{|l|}{ PAD } \\
\hline Yes & $45(56.3 \%)$ \\
\hline No & $35(43.8 \%)$ \\
\hline CBD diameter (mm) & $20.33 \pm 5.74$ \\
\hline Distal CBD arm (mm) & $37.30 \pm 12.36$ \\
\hline CBD angle & $143.53 \pm 16.06$ \\
\hline CBD angle $\leq 135$ & $40(50.0 \%)$ \\
\hline \multicolumn{2}{|l|}{ Laboratory findings } \\
\hline Total bilirubin (mg/dL) & $3.26 \pm 2.98$ \\
\hline $\operatorname{AST}(\mathbf{U} / \mathbf{L})$ & $165.28 \pm 226.06$ \\
\hline $\operatorname{ALT}(\mathbf{U} / \mathbf{L})$ & $165.91 \pm 161.59$ \\
\hline $\operatorname{ALP}(\mathbf{U} / \mathbf{L})$ & $231.19 \pm 176.78$ \\
\hline
\end{tabular}

Table 2. Efficacy evaluation.

\begin{tabular}{lc}
\hline Total $(\mathbf{n}=\mathbf{8 0})$ & \\
\hline Overall success rate & $78 / 80(97.5 \%)$ \\
Success at first ERCP & $69 / 80(86.3 \%)$ \\
Mechanical lithotripty & $0(0 \%)$ \\
\hline
\end{tabular}

Table 3. Safety evaluation.

\begin{tabular}{lc}
\hline Total $(\mathbf{n}=\mathbf{8 0})$ & \\
\hline Overall major complications & $5(6.3 \%)$ \\
Complication & \\
Pancreatitis & $3(3.8 \%)$ \\
Bleeding & $2(2.5 \%)$ \\
Perforation & $0(0 \%)$ \\
\multicolumn{1}{c}{ Death } & $0(0 \%)$ \\
\hline
\end{tabular}

high $(78 / 80,97.5 \%)$ and success rate for complete stone removal at first ERCP was 69/80 (86.3\%). Failure occurred in two patients. Too tortuous bile duct course was the reason for failure in both cases. In terms of technical failure, the rate of technical failure was $13.8 \%(11 / 80)$.
The use of mechanical lithotripsy was $0 \%(0 / 80)$. Overall complication rate was favorable $(5 / 80,6.3 \%)$. PostERCP pancreatitis was observed in three patients (two: mild, one: moderate), which was successfully treated with supportive care. Bleeding occurred in two patients. However, no life threatening bleeding episode was observed. Fortunately, we did not experience perforation in our study.

\subsection{Subgroup Analysis (Table 4)}

We compared the success group (complete stone extraction at first ERCP, $n=69$ ) with the failure group ( $\geq 2$ ERCP sessions requiring complete stone removal or complete failure, $n=11$ ). Of 11 failed patients, nine were successful at the second ERCP session and two were converted to operation. Between the two groups, baseline characteristics were similar, and Stone size, number of stones, $\mathrm{CBD}$ diameter, acute $\mathrm{CBD}$ angle $\left(<135^{\circ}\right)$, and distal CBD arm did not differ in statistical significance. However, the presence of PAD was significantly higher in the success group $(44 / 69,63.8 \%)$ than in the failure group $(1 / 11,9.1 \%)(p=0.001)$. The use of mechanical lithotripsy was similar in both groups. Overall complication rates did not differ between the two groups as well $(3 / 69,4.3 \%$ and $2 / 11,18.2 \%, p=0.137)$. PostERCP pancreatitis occurred in two cases of the success group (one: mild, one: moderate) and one case of the failure group (one: mild) $(p=0.362)$. All patients with postERCP pancreatitis were treated successfully with supportive care. Bleeding that was not serious occurred in one case in both groups, respectively $(\mathrm{p}=0.258)$. No procedure related perforation was observed in either group.

\section{DISCUSSION}

Enlarging the papillary orifice is an indispensible requisite for the endoscopic treatment of bile duct stones. It could be achieved either by cutting the biliary sphincter (endoscopic biliary sphincterotomy, EST) or by dilating the biliary sphincter (endoscopic papillary balloon dilation, EPBD). For more than three decades, EST has been performed worldwide as a primary endotherapy for extraction of bile duct stones, with a success rate of $85 \%$ to $90 \%$ for complete stone removal [12]. Nonetheless, even when performed by an expert, EST has been associated with some risk of complications, such as perforation, bleeding, pancreatitis, and, rarely, with a mortality of 0.5 to $1 \%[11,13]$.

In addition, failure of stone extraction could be expected in stones larger than $15 \mathrm{~mm}$, stones impacted in the duct, or those located above strictures or tapered ducts [14]. Since it was first described by Staritz et al. in 1983, EPBD, which dilates the biliary sphincter using a balloon typically 6 to $10 \mathrm{~mm}$ in diameter has been advo- 
Table 4. Subgroup analysis between success group and failure group at first ERCP.

\begin{tabular}{|c|c|c|c|}
\hline & Success group (69) & Failure group (11) & p-value \\
\hline Age & $71.36 \pm 10.37$ & $68.55 \pm 9.27$ & 0.399 \\
\hline Gender & & & 0.33 \\
\hline Male & $36(52.2 \%)$ & $4(36.4 \%)$ & \\
\hline Female & $33(47.8 \%)$ & $7(63.6 \%)$ & \\
\hline Balloon size (mm) & & & 0.971 \\
\hline 12 & $16(23.2 \%)$ & $2(18.2 \%)$ & \\
\hline 15 & $32(46.4 \%)$ & $5(45.5 \%)$ & \\
\hline 18 & $15(21.7 \%)$ & $3(27.3 \%)$ & \\
\hline 20 & $6(8.7 \%)$ & $1(9.1 \%)$ & \\
\hline Stone size $(\mathrm{mm})$ & $14(12-30)$ & $14(12-26)$ & 0.67 \\
\hline \multicolumn{4}{|l|}{ (Median with range) } \\
\hline Multiple stones & $39(56.5 \%)$ & $5(45.5 \%)$ & 0.493 \\
\hline PAD & & & 0.001 \\
\hline Yes & $44(63.8 \%)$ & $1(9.1 \%)$ & \\
\hline No & $25(36.2 \%$ & $10(90.9 \%)$ & \\
\hline CBD diameter (mm) & $20.28 \pm 5.53$ & $20.64 \pm 7.22$ & 0.848 \\
\hline Distal CBD arm (mm) & $37.42 \pm 12.65$ & $36.55 \pm 10.89$ & 0.829 \\
\hline CBD angle & $142.58 \pm 16.51$ & $149.45 \pm 11.79$ & 0.189 \\
\hline CBD angle $\leq 135$ & $33(47.8 \%)$ & $7(63.6 \%)$ & 0.518 \\
\hline \multicolumn{4}{|l|}{ Laboratory findings } \\
\hline Total bilirubin (mg/dL) & $3.40 \pm 3.09$ & $2.29 \pm 1.94$ & 0.273 \\
\hline $\operatorname{AST}(\mathbf{U} / \mathbf{L})$ & $156.86 \pm 213.91$ & $229.89 \pm 312.46$ & 0.365 \\
\hline $\operatorname{ALT}(\mathbf{U} / \mathbf{L})$ & $164.03 \pm 156.36$ & $180.33 \pm 207.95$ & 0.778 \\
\hline $\operatorname{ALP}(\mathbf{U} / \mathbf{L})$ & $230.64 \pm 175.79$ & $235.44 \pm 195.15$ & 0.939 \\
\hline Mechanical lithotripsy & $0(0 \%)$ & $0(0 \%)$ & NA \\
\hline \multicolumn{4}{|l|}{ Complication } \\
\hline Pancreatitis & $2(2.9 \%)$ & $1(9.1 \%)$ & 0.362 \\
\hline Bleeding & $1(1.4 \%)$ & $1(9.1 \%)$ & 0.258 \\
\hline Perforation & $0(0 \%)$ & $0(0 \%)$ & NA \\
\hline Death & $0(0 \%)$ & $0(0 \%)$ & NA \\
\hline Overall complications & $3(4.3 \%)$ & $2(18.2 \%)$ & 0.137 \\
\hline
\end{tabular}

PAD: periampullary diverticulum; CBD: common bile duct; AST: aspartate aminotransferase; ALT: alanine aminotransferase; ALP: alkaline phosphatase; ERCP: endoscopic retrograde cholangiopancreatography.

cated as an alternative to EST [15]. Although EPD has several advantages over EST (less likely with bleeding, perforation, and preservation of sphincter function), this procedure is associated with a high risk of pancreatitis [16]. Another major limitation of EPBD is the difficulty of removing larger stones because loosening of the biliary orifice is sometimes not adequate for extraction of larger stones [17].

Recently, large-diameter (more than $12 \mathrm{~mm}$ ) balloons have been used for papillary dilation with EST for treatment of patients with difficult bile duct stones that could not be extracted by conventional EST. According to the reports [1-9], the success rate of CBD stone clearance was similar in EPLBD compared to EST alone. Mechanical use was less frequent in EPLBD, although mechanical usage in large stones was similar. With respect to complications, EPLBD was associated with fewer complications [10].

However, ballooning time remains controversial in EPLBD [10]. In most EPLBD studies, the balloon was kept inflated for a few seconds to a minute after the waist of the balloon had disappeared on endoscopic and fluoro- 
scopic guidance.

According to one EPBD study [17], longer dilation may result in a larger orifice and facilitate stone extraction. On the contrary, a recent meta-analysis [10] of EPLBD studies demonstrated that ballooning time did not appear to alter the success rate of CBD stone clearance. However, it is generally believed that the longer duration gives a larger orifice and facilitates stone extraction; this idea might be accepted as relevant for either EPBD or EPLBD [18,19].

In the current study, the hypothesis for the immediate deflation method was as follows. First, EPLBD plus EST appears similar to EPBD in the context of balloon dilation. Compared to EPLBD, EPBD could not afford separation of the biliary and pancreatic orifices, which has a critical role in easier loosening of the orifice and reducing complications. Separation of the biliary and pancreatic orifices could be achieved by sphincterotomy prior to EPLBD. Second, creation of a larger orifice by EPLBD appeared to be achieved by not keeping the balloon inflated over a period but by gradual inflation of the dilation balloon, especially combined with EST (especially using a larger balloon, such as $18 \mathrm{~mm}$ or $20 \mathrm{~mm}$ ) and, in most cases, achievement of the disappearance of the waist of the balloon, which is an indicator for adequate balloon inflation, appears to occur when the maximal pressure of the balloon was attained. Third, very short ballooning time (10 - $12 \mathrm{~s})$ was observed in one EPLBD study [4], which was very similar to our study idea demonstrating high successful stone clearance rate and low complication rates.

In our study, overall success rate for complete stone removal using the immediate balloon deflation method was very high $(78 / 80,97.5 \%)$, which is comparable to other EPLBD studies [2-4,6,7], and the success rate at first ERCP for complete stone removal was acceptable $(69 / 80,86.3 \%)$. In addition, in our study, compared to other studies, the use of mechanical lithotripsy, which is a very important factor for assessing efficacy, was very low (actually, none). However, it is too impetuous to conclude that immediate deflation is a better technique compared to conventional ballooning time with this result. Limited number of enrolled patients in our study might have contributed to our findings. Nevertheless, in terms of efficacy, our new method of immediate deflation is not inferior to conventional ballooning time, which is routinely applied in most in hospitals. Overall major complication rate $(5 / 80,6.3 \%)$ was also acceptable, compared to that of other EPLBD studies, which ranged from $3 \%$ to $6 \%$.

Our focus for assessment of complications was on significant procedure-related bleeding or perforation. Although complications appeared to be fewer in EPLBD plus EST than in EST alone [10], life threatening bleeding [20] and perforation [21] could be caused from tear- ing of the ducts during performance of EPLBD. And, in general, longer inflation of the balloon is thought to have a compression effect on bleeding. Therefore, it was one of our concerns that when the balloon was deflated immediately in EPLBD, sudden loss of compression effect of a balloon might induce serious bleeding from a lacerated duodenal wall. However, in our study, although bleeding occurred in two patients, there was no occurrence of serious bleeding and these two patients were easily treated with supportive care. With regard to perforation, we did not experience procedure related perforation. Considering these results, acute hemorrhage and perforation following EPLBD appeared to be related not to ballooning time but to balloon over inflation, as mentioned previously by Itoi et al. [16] Procedure related death was not reported. In terms of safety, use of the immediate balloon deflation method did not result in an increase in complication rate and appears to be safe, compared to conventional ballooning time.

In sub-group analysis, similar baseline characteristics were observed between the success group and the failure group. The size of the balloon used, bile duct stone size, and number of bile duct stones did not affect stone clearance in either group. However, the presence of PAD was different. In the success group, PAD was present in $44 / 69(63.8 \%)$ patients and in only $1 / 11(9.1 \%)$ patients in the failure group $(p=0.001)$. Thus far, the impact of PAD on EPLBD has not been well studied. One recently published study reported that the presence of PAD did not affect the technical success and complications on EPLBD with limited EST for treatment of CBD stones, however, caution is required in some types of PAD [22]. In subgroup analysis, our result regarding the presence of PAD seemed very difficult to interpret. This result should not lead to the conclusion of a positive influence of the presence of PAD on the technical success in EPLBD. One possible explanation is that a small sample size of the failure group might have caused this questionable result. Another possible explanation is that the presence of PAD could cause the endoscopist to try harder to complete stone extraction in a single session.

No significant significance in CBD diameter, distal $\mathrm{CBD}$ arm, and CBD angulations was observed in either group. This finding suggests that in EPLBD therapy, anatomical variation of bile duct might play a minimal role in removal of bile duct stones. Either overall major complication rates or individual major complications between the two groups were similar.

Retrospective analysis is a major limitation in our study. A small sample size is another major limitation, which might have resulted in underestimation of complication rates. These limitations should also be considered for interpretation of results in subgroup analysis. However, being naive to ERCP in all enrolled patients is 
a strong point of our study, which might lower the chance of bias.

In conclusion, our new method for immediate balloon deflation in EPLBD is effective and safe and could be considered for use in clinical practice. In addition, reducing procedure time and patient's discomfort might be another expected benefit of our study, although they were not evaluated in this study. We hope that a large prospective study will be conducted in order to confirm our results in the near future.

\section{REFERENCES}

[1] Ersoz, G., Tekesin, O., Ozutemiz, A.O., et al. (2003) Biliary sphincterotomy plus dilation with a large balloon for bile duct stones that are difficult to extract. Gastrointestinal Endoscopy, 57, 156-159. doi:10.1067/mge.2003.52

[2] Heo, J.H., Kang, D.H., Jung, H.J., et al. (2007) Endoscopic sphicterotomy plus large-balloon dilation versus endoscopic sphincterotomy for removal of bile-duct stones. Gastrointestinal Endoscopy, 66, 720-726. doi:10.1016/j.gie.2007.02.033

[3] Rebelo, A., Ribeiro, P.M., Correia, A.P., et al. (2012) Endoscopic papillary large balloon dilation after limited sphincterotomy for difficult biliary stones. World Journal of Gastrointestinal Endoscopy, 16, 180-184. doi:10.4253/wjge.v4.i5.180

[4] Stefanidis, G., Viazis, N., Pleskow, D., et al. (2011) Large balloon dilation vs. mechanical lithotripsy for the management of large bile duct stones: A prospective randomized study. American Journal of Gastroenterology, 106, 278-285. doi:10.1038/ajg.2010.421

[5] Attasarany, S., Cheon, Y.K., Vittal, H., et al. (2008) Large-diameter biliary orifice balloon dilation to aid in endoscopic bile duct stone removal: A multicenter series. Gastrointestinal Endoscopy, 67, 1046-1052. doi:10.1016/i.gie.2007.08.047

[6] Itoi, T., Itokawa, F., Sofuni, A., et al. (2009) Endoscopic sphincterotomy combined with large balloon dilation can reduce the procedure time and fluoroscopy time for removal of large bile duct stones. American Journal of Gastroenterology, 104, 560-565. doi:10.1038/ajg.2008.67

[7] Kim, T.H., Oh, H.J., Lee, J.Y., et al. (2011) Can a small endoscopic sphincterotomy plus a large-ballooon dilation reduce the use of mechanical lithotripsy in patients with large bile duct stones? Surgical Endoscopy, 25, 33303337. doi:10.1007/s00464-011-1720-3

[8] Dragnov, P.V., Evan, W., Fazel, A., et al. (2009) Large size balloon dilation of the ampulla after biliary sphincterotomy can facilitate endoscopic extraction of difficult bile duct stones. Journal of Clinical Gastroenterology, 43, 782-786. doi:10.1097/MCG.0b013e31818f50a2

[9] Lee, D.K. and Han, J.W. (2012) Endoscopic papillary large balloon dilation: Guidelines for pursuing zero mortality. Clinical Endoscopy, 45, 299-304. doi:10.5946/ce.2012.45.3.299

[10] Feng, Y., Zhu, H., Chen, X., et al. (2012) Comparison of endoscopic papillary large balloon dilation and endoscopic sphincterotomy for retrieval of choledocholithiasis: A meta-analysis of randomized controlled trials. Journal of Gastroenterology, 47, 655-663. doi:10.1007/s00535-012-0528-9

[11] Cotton, P.B., Lehman, G. and Vennes G. (1991) Endoscopic sphincterotomy, complications and their management: An attempt at consensus. Gastrointestinal Endoscopy, 37, 383-393. doi:10.1016/S0016-5107(91)70740-2

[12] Foutch, G. (1991) Endoscopic management of large common duct stones. American Journal of Gastroenterology, 86, 1561-1565.

[13] Freeman, M.L., Nelson, D.B., Sheerman, S., et al. (1996) Complications of endoscopic biliary sphincterotomy. New England Journal of Medicine, 335, 909-918. doi:10.1056/NEJM199609263351301

[14] McHenry, I. and Lehman, G. (2006) Difficult bile duct stones. Current Treatment Options in Gastroenterology, 9, 123-132. doi:10.1007/s11938-006-0031-6

[15] Staritz, M., Ewe, K. and Meyer zum Bushcenfelde, K.H. (1983) Endoscopic papillary dilation (EPD) for the treatment of common bile duct stones and papillary stenosis. Endoscopy, 15, 197-198. doi:10.1055/s-2007-1021507

[16] DiSario, J.A., Freeman, M.L., Bjorkman, D.J., et al. (2004) Endoscopic balloon dilation compared with sphincterotomy for extraction of bile duct stones. Gastronenterology, 127, 1291-1299. doi:10.1053/j.gastro.2004.07.017

[17] Baron, T.H. and Harewood, G.C. (2004) Endoscopic balloon dilation of the biliary sphicnter compared to endoscopic biliary sphincterotomy for removal of common bile duct stones during ERCP: A metaanalysis of randomized, controlled trials. American Journal of Gastroenterology, 99, 1455-1460. doi:10.1111/j.1572-0241.2004.30151.x

[18] Liao, W.C., Lee, C.T., Chang, C.Y., et al. (2010) Randomized trial of 1-minute versus 5-minute endoscopic balloon dilation for extraction of bile duct stones. Gastrointestinal Endoscopy, 72, 1154-1162. doi:10.1016/j.gie.2010.07.009

[19] Attam, R. and Freeman, M.L. (2010) Endoscopic paillary balloon dilation for stone extraction: If, when, and for how long? Gastrointestinal Endoscopy, 72, 1163-1166. doi:10.1016/j.gie.2010.10.012

[20] Lee, T.H., Park, S.H., Lee, C.K., et al. (2009) Life threatening hemorrhage following large balloon endoscopic papillary dilation successfully treated with angiographic embolization. Endoscopy, 41, E241-E242.

[21] Katsinelos, P., Chatzimavroudis, G., Pilipilidis, I., et al. (2008) Benign retropneuomoperitoneum developed after endoscopic sphincterotomy and large balloon dilation of biliary sphincter for removal of large biliary stones: A case report. Cases Journal, 1, 279. doi:10.1186/1757-1626-1-279

[22] Kim, H.W., Kang, D.H., Choi, C.W., et al. (2010) Limited endoscopic sphincterotomy plus large balloon dilation for choledocholithiasis with periampullary diverticula. World Journal of Gastroenterology, 16, 4335-4340. doi:10.3748/wjg.v16.i34.4335 